\title{
BMJ Open Association between healthy lifestyle score changes and quality of life and health-related quality of life: a longitudinal analysis of South Korean panel data
}

\author{
Fatima Nari (D) , ${ }^{1,2}$ Wonjeong Jeong, ${ }^{1,2}$ Bich Na Jang, ${ }^{1,2}$ Hyeon Ji Lee, ${ }^{1,2}$ \\ Eun-Cheol Park (1) ${ }^{3}$
}

To cite: Nari F, Jeong W, Jang BN, et al. Association between healthy lifestyle score changes and quality of life and health-related quality of life: a longitudinal analysis of South Korean panel data. BMJ Open 2021;11:e047933. doi:10.1136/ bmjopen-2020-047933

- Prepublication history and additional supplemental material for this paper are available online. To view these files, please visit the journal online (http://dx.doi.org/10.1136/ bmjopen-2020-047933).

Received 14 December 2020 Accepted 01 October 2021

\section{Check for updates}

\section{Author(s) (or their} employer(s)) 2021. Re-use permitted under CC BY-NC. No commercial re-use. See rights and permissions. Published by BMJ.

${ }^{1}$ Department of Public Health, Graduate School, Yonsei University, Seodaemun-gu, Korea (the Republic of) ${ }^{2}$ Yonsei University Institute of Health Services Research, Seodaemun-gu, Korea (the Republic of)

${ }^{3}$ Department of Preventive Medicine, Yonsei University College of Medicine, Seodaemun-gu, Seoul, Korea (the Republic of)

Correspondence to

Eun-Cheol Park;

ecpark@yuhs.ac

\section{ABSTRACT}

Objectives We aimed to determine the influence of changes in the aggregate score of healthy lifestyle factors on health-related quality of life (HRQOL) and overall quality of life (QOL) in the Korean older adult population.

Design This study used a longitudinal design.

Setting and participants Data on 9474 participants aged 45 years or older were extracted from the Korean Longitudinal Study on Aging for the period 2006-2016. A composite score of four lifestyle factors (smoking, drinking, physical activity and body mass index) was calculated, and biennial changes in aggregate score were computed.

Primary and secondary outcome measures The primary outcomes were HRQOL and QOL.

Results Generalised estimating equation analysis results showed that those with healthy lifestyle score changes from 'Low-High' $(\beta=-0.987, \mathrm{p}=0.002 ; \beta=-1.288$, $\mathrm{p}<0.0001)$, 'High-Low' $\beta=-1.281, \mathrm{p}<0.0001 ; \beta=-1.952$, $\mathrm{p}<0.0001)$ and 'Low-Low' $(\beta=-1.552, \mathrm{p}<0.0001$; $\beta=-2.398, \mathrm{p}<0.0001)$ groups were more likely to be have lower HRQOL and QOL estimates than those in 'HighHigh' group. Female gender, older age and depression had a more negative impact on HRQOL, while male gender and younger age had a more negative impact on QOL, especially in the Low-Low group. The relationship between changes in scores and HRQOL and QOL varied across different elements of healthy lifestyle scores. Changes in physical activity, drinking and smoking status were significantly associated with lower HRQOL and QOL. Conclusion The findings suggest an association between a low healthy lifestyle score and poor quality of life, in both general and health-related aspects. Strategies targeting the Korean ageing demographic to promote a healthier lifestyle should be encouraged.

\section{INTRODUCTION}

In recent years, the general trend towards an ageing population has increased exponentially worldwide. Between 2015 and 2050, the proportion of the world's population over 60 years is expected to increase from $12 \%$ to $22 \%$, according to the WHO. ${ }^{1}$ In 2015 , the
Strengths and limitations of this study

- A large, nationally representative sample of Korean older adults was included in this study.

- We analysed biennial changes in a composite score of lifestyle factors longitudinally to determine their influence on overall and health-related quality of life.

- Our findings could not be generalised to other populations because of the homogeneous nature of our study sample, lack of standardised cut-off points, and categorisations of health behaviours.

Korean National Statistical Office reported that the number of adults aged 65 years or older accounted for $13.2 \%$ of the total population, which is expected to rise up to $40 \%$ by $2060 .^{2}$

The health and socioeconomic burden of ageing-related problems are becoming a great concern as life expectancy improves. Additionally, many people believe that a good quality of life (QOL) is equally important as the length of life. The WHO defines QOL as the 'individual's perception of their position in life in the context of the culture and value systems in which they live and in relation to their goals, expectations, standard and concerns'. ${ }^{3}$ It is a broad concept revolving around how an individual's life is affected in an intricate way by various factors such as the person's physical health, psychological state, level of independence and social relationships. ${ }^{3}$ In comparison, health-related quality of life (HRQOL) is a much narrower domain, characterised by influence of multidimensional variables, that considers the physical as well as mental components related to health. ${ }^{4}$ In other words, while HRQOL involves the assessment of QOL related to health and 


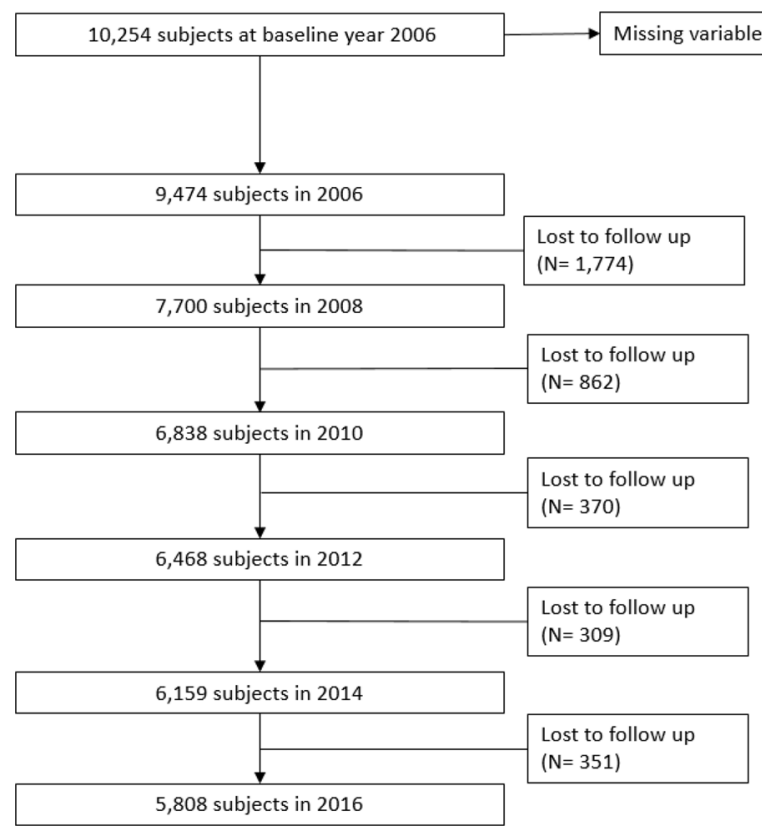

Figure 1 Flowchart of the study participants from 2006 to 2016.

disease, QOL takes into account non-medical concepts as well. ${ }^{5}$

Factors affecting the QOL of the ageing population, both general and health-related, are numerous. Maintaining healthy behaviours in older age, such as a balanced diet, refraining from smoking, and regular physical activity, all contribute to reducing the risk of chronic diseases and mortality, as well as improving physical and mental health. ${ }^{3}$ Health behaviours are general indicators of HRQOL in particular. ${ }^{6} 7$ In addition, prior evidence suggests that health risk behaviours such as physical inactivity, drinking and smoking are very likely to occur simultaneously in ageing individuals. ${ }^{8}$

In previous studies, a cluster of lifestyle risk factors was associated with a reduction in capacity for activities of daily living ${ }^{9}$ and was strongly correlated with morbidity and mortality. ${ }^{10}$ In addition, and in older adults, it was also linked to increased hospitalisations and outpatient care use. $^{11}$

While the influence of health behaviours on HRQOL is an essential finding, the effect of an unhealthy lifestyle on an individual's subjective evaluation of QOL and overall aspects of physical, psychological and social wellbeing should be emphasised as well. Moreover, evidence regarding the degree of impact of lifestyle factors on HRQOL and QOL of Korean older adults is still lacking. Therefore, the present study aimed to investigate the association between changes in a composite score of healthy lifestyle factors with HRQOL and QOL in middle-aged and older Korean adults.

\section{METHODS}

We utilised data extracted from the first to sixth waves (2006-2016) of the Korean Longitudinal Study of Aging
(KLoSA). Since 2006, the Korea Labor Institute has collected nationally representative data through use of multistage, stratified probability sampling design to randomly select participants from all regions in Korea with the exception of Jeju Island. The KLoSA panel data were established through repeated surveys in the same sample biennially, thereby reflecting trends over time in middle-aged and older residents aged 45 years or older residing in Korea. ${ }^{12}$ The number of participants included in the original survey in 2006 was 10254 , followed by 8875 in 2008, 8229 in 2010, 7813 in 2012, 8387 in 2014 and 7893 participants in 2016. More information about the survey can be found on the panel survey organisation website (https://survey.keis.or.kr/eng/klosa/klosa01. jsp). After excluding those with missing data and those who failed to follow-up, a total of 9474 participants were included in our study. The detailed flow of the participants in our study is depicted in figure 1.

\section{Patient and public involvement}

No patient involved.

\section{Measures}

Quality of life and health-related quality of life

Comprehensive assessment of overall QOL and HRQOL was carried out using an instrument similar to the EuroQOL visual analogue scale (EQ-VAS), where participants provided a subjective score ranging from 0 to 100 on their perceived QOL. The VAS is an instrument with good reliability and validity compared with multi-item questionnaires. ${ }^{13}$

\section{Healthy lifestyle score}

We computed the healthy lifestyle score by assigning a score to each of the following healthy lifestyle factors: (1) smoking status: never smokers (optimal), past smokers (intermediate) and current smokers (poor). (2) Drinking status: never or past drinker was classified as optimal; current drinking behaviour was further classified using the CAGE questionnaire (cutting down, annoyance by criticism, guilty feeling and eye-openers) provided in the KLoSA. If the current drinker answered 'yes' to one or none of the questions, they were classified as normal drinkers (intermediate); otherwise, they were classified as heavy drinkers (poor). ${ }^{14}$ (3) Physical activity was categorised as exercising more than 150 min weekly (optimal), less than $150 \mathrm{~min}$ (intermediate) and never (poor). (4) Body mass index (BMI) was categorised using the criteria set by WHO to define obesity in an Asian population: a BMI higher than $25 \mathrm{~kg} / \mathrm{m}^{2}$ and an underweight BMI of less than $18 \mathrm{~kg} / \mathrm{m}^{2}$ was rated as poor; slightly overweight BMI of $23-24.9 \mathrm{~kg} / \mathrm{m}^{2}$ was classified as intermediate and a BMI of $18-22.9 \mathrm{~kg} / \mathrm{m}^{2}$ was optimal. ${ }^{15}$ A score of 0 points was assigned to poor, 1 point for intermediate and 2 points for optimal. The maximum score was 8 points, and the scores were divided into two categories, based on the median, which were $0-5$ points for the low group and $6-8$ points for the high group. We detected 2-year changes in 
participants' healthy lifestyle by investigating the lagged healthy lifestyle score in the prior year and scores in the following year over 2 consecutive years (2006-2008, 2008-2010, 2010-2012, 2012-2014 and 2014-2016). Therefore, we grouped the scores into four categories: (1) High-High, (2) Low-High, (3) High-Low and (4) Low-Low. Further subgroup analysis of individual components of the composite lifestyle score was conducted by regrouping the poor as the low group and intermediate and optimal as the high group. In addition, the number of participants in each healthy lifestyle component were expressed as percentages in online supplemental table 1.

\section{Covariates}

Data regarding sociodemographic characteristics and health-related variables were added as potential confounders in this study. Sociodemographic characteristics included gender, age (45-54, 55-64 and $\geq 65$ years), education level (middle school or lower, high school degree and university degree or higher) and income level per month (low, middle low, middle high and high). Additionally, marital status was classified into married and unmarried, while region was categorised as urban or rural. Economic activity was classified based on whether the individual was economically active or inactive.

Participants was grouped into the 'Yes' category if they participated in at least one social activity; otherwise, they were grouped into the 'No' category. Depression was classified based on the Center for Epidemiological Studies Depression Scale-10 classification. Cognitive function was classified as normal based on whether the respondents' score on the Korean Mini-Mental State Examination was higher than 24 points; otherwise, it was classified as abnormal. ${ }^{16}$ Difficulties in activities of daily living (ADL) and instrumental activities of daily living (IADL) were measured based on whether the individual experienced at least one limitation in any daily necessary tasks (getting dressed, washing one's face and hands, bathing, eating meals, leaving a room and using the toilet) for ADL, and social function-related tasks (companionship and mental support, transportation, making phone calls, finance management, cooking meals, doing household chores, laundry, shopping and taking medications) for IADL. The chronic diseases included in this study were hypertension, diabetes, cancer, heart disease, lung disease, liver disease, cerebrovascular disease, psychiatric disease and arthritis; the number of comorbidities were grouped into three categories: 0,1 and $\geq 2$ diseases. Self-rated health was classified as good, normal or bad.

2-year lagged multivariable generalised estimating equation (GEE) model with an unstructured working correlation was used to longitudinally examine impact of healthy lifestyle score changes on HRQOL and QOL, after controlling for confounders. The GEE is considered an extension of the generalised linear model and allows for analysis of repeated panel data such as the KLoSA by taking within-subject correlation into account and produces estimates based on the mean regression parameters. ${ }^{17}$ Data from a total of six waves (2006-2016) were used in this study, and thus, repeated measurements for each participant were conducted up to five times. All data analyses were performed using the statistical package SAS V.9.4, and pvalues less than 0.05 , were considered statistically significant.

\section{RESULTS}

Table 1 lists the general characteristics of the population of 7700 people at the first time point of change in healthy lifestyle score, which was the baseline period of 2006-2008. The mean HRQOL was 57.1 (SD: 21.6) for the High-High score group, 53.9 (SD: 20.4) for the LowHigh score group, 53.7 (SD: 22.2) for the High-Low group and 56.1 (SD: 21.6) for the Low-Low score group. The mean QOL was 63.4 (SD: 18.7) for the High-High score group, 60.4 (SD: 18.5) for the Low-High score group, 58.7 (SD: 19.1) for the High-Low group and 59.8 (SD: 18.5) for the Low-Low score group.

Table 2 shows the adjusted effect of changes in healthy lifestyle scores on HRQOL and QOL. Compared with those in the High-High group, the HRQOL estimate was $\beta=-0.987(\mathrm{p}=0.002)$ for the Low-High group, while the estimate was $\beta=-1.281(\mathrm{p}<0.0001)$ for those in the HighLow group; for those in the Low-Low group, the estimate was $\beta=-1.522(\mathrm{p}<0.0001)$. Compared with the High-High group, the QOL estimate was $\beta=-1.288$ in the Low-High group $(\mathrm{p}<0.0001), \beta=-1.952(\mathrm{p}<0.0001)$ in the High-Low group and $\beta=-2.398(\mathrm{p}<0.0001)$ in the Low-Low group.

Table 3 shows the subgroup analysis of gender, age and depression with changes in healthy lifestyle scores for HRQOL and QOL. For HRQOL, the Low-Low score group, in particular, had a lower estimate for females $(\beta=-1.639 ; \mathrm{p}<0.0001)$; however, for QOL, males had a lower estimate $(\beta=-2.791 ; \mathrm{p}<0.0001)$. Older participants aged more than 65 years had lower HRQOL $(\beta=-1.694$; $\mathrm{p}<0.0001)$, while younger participants aged $45-54$ years had a lower QOL $(\beta=-3.786, \mathrm{p}<0.0001)$. Individuals who were depressed had a lower HRQOL $(\beta=-1.672$, $\mathrm{p}<0.0001$ ).

Table 4 shows the subgroup analysis of changes in each component of healthy lifestyle scores within HRQOL and QOL. Compared with the High-High score group, the Low-Low score group showed a statistically significantly lower estimate for both HRQOL $(\beta=-3.722 ; \mathrm{p}<0.0001)$ and QOL $(\beta=-4.026 ; \mathrm{p}<0.0001)$ for change in physical activity. For smoking status change, both HRQOL and QOL showed significantly lower estimates in the Low-Low score group, that is, $\beta=-1.362(\mathrm{p}<0.0001)$ and $\beta=-2.907$ $(\mathrm{p}<0.0001)$, respectively. For drinking status change, both HRQOL and QOL showed the lowest estimates in the Low-Low group, that is, $\beta=-1.282(\mathrm{p}=0.085)$ and $\beta=-2.780 \quad(\mathrm{p}=0.0002)$, respectively, although only $\mathrm{QOL}$ was significant. The results did not show any statistically significant changes in the BMI status for both HRQOL and QOL. 
Open access

Table 1 General characteristics of the study population at baseline (2006-2008) $(n=7700)$

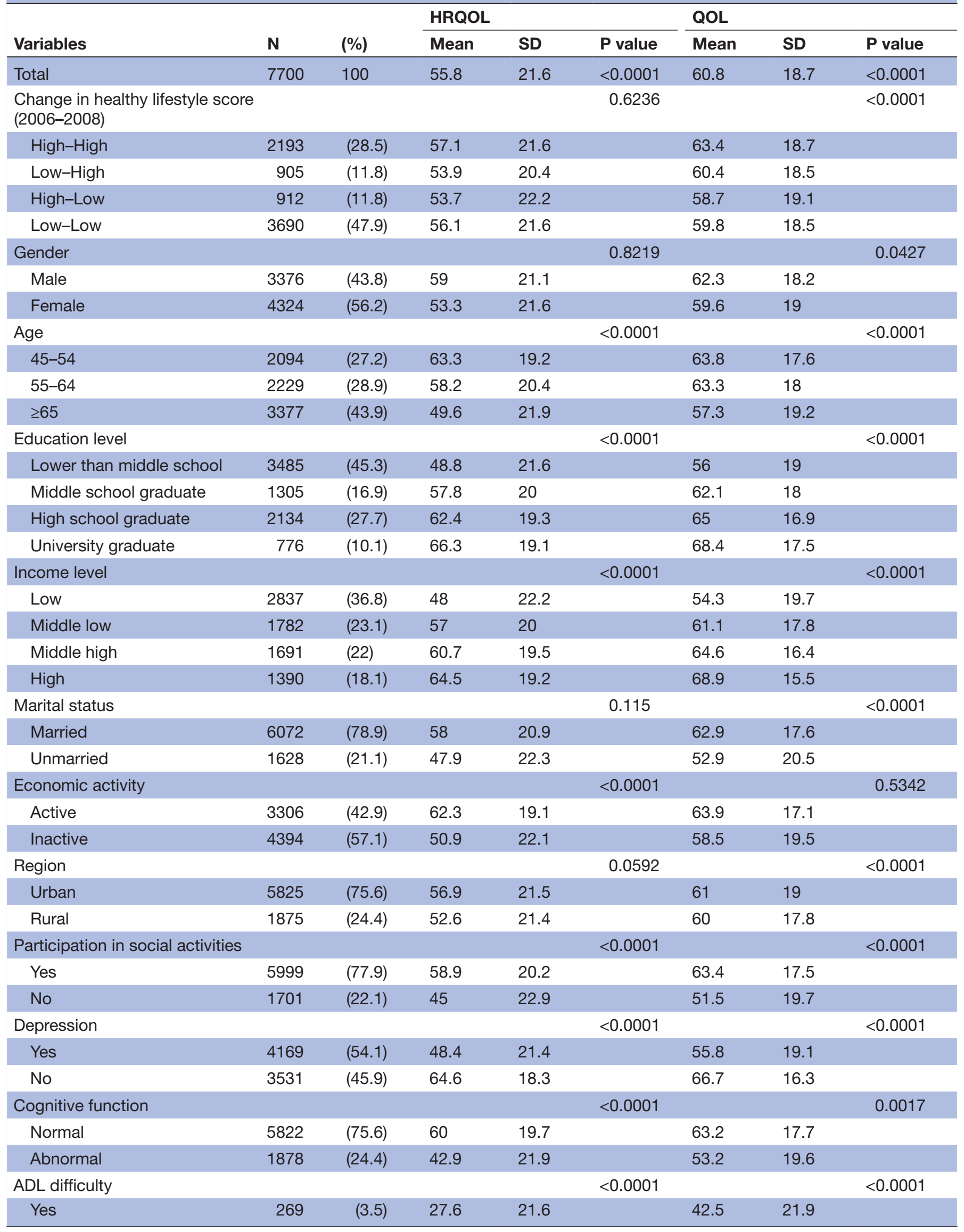


Table 1 Continued

\begin{tabular}{|c|c|c|c|c|c|c|c|c|}
\hline \multirow[b]{2}{*}{ Variables } & \multirow[b]{2}{*}{$\mathbf{N}$} & \multirow[b]{2}{*}{ (\%) } & \multicolumn{3}{|c|}{ HRQOL } & \multicolumn{3}{|l|}{ QOL } \\
\hline & & & Mean & SD & $P$ value & Mean & SD & $P$ value \\
\hline No & 7431 & $(96.5)$ & 56.9 & 20.9 & & 61.4 & 18.2 & \\
\hline IADL difficulty & & & & & 0.0031 & & & $<0.0001$ \\
\hline Yes & 852 & (11.1) & 41.8 & 23.6 & & 50.9 & 20.7 & \\
\hline No & 6848 & $(88.9)$ & 57.6 & 20.7 & & 62 & 18.1 & \\
\hline Self-rated health & & & & & $<0.0001$ & & & $<0.0001$ \\
\hline Good & 3618 & (47) & 66.3 & 17.1 & & 66.4 & 15.8 & \\
\hline Normal & 2399 & $(31.2)$ & 53.8 & 18 & & 59.6 & 18.1 & \\
\hline Bad & 1683 & (21.9) & 36.2 & 20.3 & & 50.4 & 20.4 & \\
\hline Number of chronic diseases & & & & & $<0.0001$ & & & 0.002 \\
\hline 0 & 3506 & $(45.5)$ & 62.6 & 19.1 & & 63.6 & 17.2 & \\
\hline 1 & 2328 & (30.2) & 54.5 & 21 & & 61.1 & 18.6 & \\
\hline$\geq 2$ & 1866 & $(24.2)$ & 44.7 & 21.7 & & 55.1 & 20.3 & \\
\hline
\end{tabular}

$\mathrm{ADL}$, activities of daily living; HRQOL, health-related quality of life; IADL, instrumental activities of daily living; QOL, quality of life.

\section{DISCUSSION}

The primary purpose of our study was to investigate the influence of 2-year healthy lifestyle score changes on HRQOL and QOL using longitudinal models to analyse a nationally representative sample of South Korean older adults. Our findings suggested that poor QOL in the general and health-related aspects was associated with presence or transitions from and to a low healthy lifestyle score. In addition, a low lifestyle score had a higher negative correlation with overall QOL than HRQOL. One possible explanation could be that QOL is a holistic concept, encompassing health, well-being, financial stability, social relationships, among others. Therefore, the influence of a low healthy lifestyle score had a greater impact on the general QOL than the HRQOL measure alone.

Prior research revealed that adults with healthier behaviour patterns ${ }^{18}$ were more likely to report more positive perceptions of their health and QOL. ${ }^{19}$ Although a plethora of studies used individual assessments of health behaviours, these may have provided incomplete estimation of the contribution of a healthy lifestyle to QOL. ${ }^{20}$ Moreover, prior evidence indicates that possibly, a low HRQOL is equivalent to the loss of health as perceived by older adults, and therefore, health-promoting behaviours such as regular physical activity and smoking cessation seem to be good indicators of QOL. ${ }^{21} 22$

Our study has important methodological implications as research that demonstrates a relationship between changes in health behaviours over time (especially using a composite lifestyle score) in older people and QOL requires further exploration. Considering that a majority of prior studies used single or stationary assessments of health behaviours, observing the influence of dynamic change of an aggregate of different health behaviours over time on QOL may provide novel information.
A study conducted in Ireland revealed that healthier clusters (former smokers, temperate and healthy lifestyle) reported better self-rated health and higher QOL. ${ }^{23} \mathrm{~A}$ prior study conducted in Korea also showed that current smoking, regular exercise and current alcohol consumption in men largely influenced their perceived QOL. ${ }^{2}$

Further subgroup analysis identified gender and age differences, supporting previous evidence. A study conducted showed that men reported a significantly better HRQOL than women. ${ }^{24}$ Additionally, an interesting finding was that QOL estimates showed improvement with increasing age in all patterns of healthy lifestyle scores. In other words, younger participants reported a significantly worse QOL than their older counterparts.

Moreover, depression in the constant Low-Low group was also shown to be a critical indicator of poor HRQOL, suggesting that deteriorating mental condition and combination of unhealthy behaviours significantly affects HRQOL in ageing adults. Depressive symptoms are strongly associated with unhealthy and risky lifestyle behaviours and may lower HRQOL. ${ }^{25-27}$

Other assessments, particularly constant physical inactivity, were also significant indicators in the older adult population. ${ }^{28}$ Physical activity is a protective factor for QOL. ${ }^{29}$ Physical exercise such as walking is suggested to improve QOL and health, especially in women. ${ }^{30}$ Although HRQOL and QOL vis-a-vis BMI status change were not significant, change from Low-High score surprisingly had the lowest estimates of both HRQOL and QOL. As both underweight and obese BMI were grouped in the low score group, our results can partially be explained by presence of an 'obesity paradox', wherein individuals with obesity showed better HRQOL and QOL than those who were normal. ${ }^{31}$

Current smoking has been reported significantly associated with decreased QOL among older adults. ${ }^{32-34}$ 
Open access

Table 2 Association of change in healthy lifestyle score and HRQOL/QOL

\begin{tabular}{|c|c|c|c|c|c|c|}
\hline \multirow[b]{2}{*}{ Variables } & \multicolumn{3}{|l|}{ HRQOL } & \multicolumn{3}{|l|}{ QOL } \\
\hline & $\beta$ & SD & $P$ value & $\beta$ & SD & $P$ value \\
\hline \multicolumn{7}{|c|}{ Change in healthy lifestyle score } \\
\hline High-High & Ref. & & & Ref. & & \\
\hline Low-High & -0.987 & 0.31 & 0.002 & -1.288 & 0.278 & $<0.0001$ \\
\hline High-Low & -1.281 & 0.314 & $<0.0001$ & -1.952 & 0.286 & $<0.0001$ \\
\hline Low-Low & -1.552 & 0.261 & $<0.0001$ & -2.398 & 0.245 & $<0.0001$ \\
\hline \multicolumn{7}{|l|}{ Gender } \\
\hline Male & Ref. & & & Ref. & & \\
\hline Female & -0.253 & 0.286 & 0.377 & 0.74 & 0.282 & 0.009 \\
\hline \multicolumn{7}{|l|}{ Age } \\
\hline $45-54$ & -2.385 & 0.372 & $<0.0001$ & -3.043 & 0.347 & $<0.0001$ \\
\hline $55-64$ & -0.955 & 0.262 & 0 & -1.151 & 0.248 & $<0.0001$ \\
\hline$\geq 65$ & Ref. & & & Ref. & & \\
\hline \multicolumn{7}{|l|}{ Education level } \\
\hline Lower than middle school & -4.858 & -4.82 & 0.469 & $<0.0001$ & -4.348 & 0.471 \\
\hline Middle school graduate & -3.089 & -3.111 & 0.47 & $<0.0001$ & -3.075 & 0.48 \\
\hline High school graduate & -1.75 & 0.423 & $<0.0001$ & -2.046 & 0.425 & $<0.0001$ \\
\hline University graduate & Ref. & & & Ref. & & \\
\hline \multicolumn{7}{|l|}{ Income level } \\
\hline Low & -3.688 & 0.341 & $<0.0001$ & -6.073 & 0.318 & $<0.0001$ \\
\hline Middle low & -2.08 & 0.315 & $<0.0001$ & -3.971 & 0.291 & $<0.0001$ \\
\hline Middle high & -0.978 & 0.298 & 0.001 & -2.221 & 0.268 & $<0.0001$ \\
\hline High & Ref. & & & Ref. & & \\
\hline \multicolumn{7}{|l|}{ Marital status } \\
\hline Married & Ref. & & & Ref. & & \\
\hline Unmarried & -0.895 & 0.319 & 0.005 & -3.111 & 0.338 & $<0.0001$ \\
\hline \multicolumn{7}{|l|}{ Economic activity } \\
\hline Active & Ref. & & & Ref. & & \\
\hline Inactive & -2.485 & 0.239 & $<0.0001$ & -0.722 & 0.223 & 0.001 \\
\hline \multicolumn{7}{|l|}{ Region } \\
\hline Urban & 0.316 & 0.278 & 0.257 & -2.06 & 0.274 & $<0.0001$ \\
\hline Rural & Ref. & & & Ref. & & \\
\hline \multicolumn{7}{|l|}{ Participation in social activities } \\
\hline Yes & Ref. & & & Ref. & & \\
\hline No & -2.87 & 0.256 & $<0.0001$ & -3.056 & 0.244 & $<0.0001$ \\
\hline \multicolumn{7}{|l|}{ Depression } \\
\hline Yes & -4.846 & 0.195 & $<0.0001$ & -4.291 & 0.179 & $<0.0001$ \\
\hline No & Ref. & & & Ref. & & \\
\hline \multicolumn{7}{|l|}{ Cognitive function } \\
\hline Normal & Ref. & & & Ref. & & \\
\hline Abnormal & -3.808 & 0.266 & $<0.0001$ & -2.102 & 0.247 & $<0.0001$ \\
\hline \multicolumn{7}{|l|}{ ADL difficulty } \\
\hline Yes & -5.354 & 0.67 & $<0.0001$ & -4.401 & 0.656 & $<0.0001$ \\
\hline No & Ref. & & & Ref. & & \\
\hline
\end{tabular}


Table 2 Continued

\begin{tabular}{|c|c|c|c|c|c|c|}
\hline \multirow[b]{2}{*}{ Variables } & \multicolumn{3}{|l|}{ HRQOL } & \multicolumn{3}{|l|}{ QOL } \\
\hline & $\beta$ & SD & $P$ value & $\beta$ & SD & $P$ value \\
\hline Yes & -2.451 & 0.367 & $<0.0001$ & -2.022 & 0.35 & $<0.0001$ \\
\hline No & Ref. & & & Ref. & & \\
\hline \multicolumn{7}{|c|}{ Self-rated health } \\
\hline Good & Ref. & & & Ref. & & \\
\hline Normal & -5.105 & 0.209 & $<0.0001$ & -2.371 & 0.191 & $<0.0001$ \\
\hline Bad & -16.223 & 0.333 & $<0.0001$ & -6.925 & 0.301 & $<0.0001$ \\
\hline \multicolumn{7}{|c|}{ Number of chronic diseases } \\
\hline 0 & Ref. & & & Ref. & & \\
\hline 1 & -2.135 & 0.266 & $<0.0001$ & 0.094 & 0.253 & 0.711 \\
\hline$\geq 2$ & -4.605 & 0.31 & $<0.0001$ & -0.837 & 0.297 & 0.005 \\
\hline
\end{tabular}

$\beta$, regression coefficient; ADL, activities of daily living; HRQOL, health-related quality of life; IADL, instrumental activities of daily living; QOL, quality of life.

Similar to our main findings, continuous smoking (LowLow) over a span of 2 years showed a greater association with poor QOL than HRQOL. A prior smoking cessation trial study compared the effects of quitting smoking versus continuing smoking on both HRQOL and global
QOL. Results suggested that compared with continuing smoking, quitting smoking showed improvement in both HRQOL and global QOL, despite the association being stronger with HRQOL which was different from our present study. ${ }^{22}$ Our study also revealed that constant

Table 3 Subgroup analysis of changes in healthy lifestyle score and HRQOL/QOL, stratified by covariates

\begin{tabular}{|c|c|c|c|c|c|c|c|c|c|c|c|c|}
\hline \multirow[b]{3}{*}{ Variables } & \multicolumn{12}{|c|}{ Changes in healthy lifestyle score } \\
\hline & \multicolumn{3}{|c|}{ High-High } & \multicolumn{3}{|c|}{ Low-High } & \multicolumn{3}{|c|}{ High-Low } & \multicolumn{3}{|c|}{ Low-Low } \\
\hline & $\beta$ & SD & $P$ value & $\beta$ & SD & $P$ value & $\beta$ & SD & $P$ value & $\beta$ & SD & $P$ value \\
\hline \multicolumn{13}{|l|}{ Gender } \\
\hline Male & Ref. & & & -1.135 & 0.54 & 0.036 & -1.718 & 0.579 & 0.003 & -1.574 & 0.448 & 0.0004 \\
\hline \multicolumn{13}{|l|}{ Age } \\
\hline $45-54$ & Ref. & & & -0.589 & 0.842 & 0.484 & -0.792 & 0.844 & 0.348 & -1.367 & 0.679 & 0.0441 \\
\hline $55-64$ & Ref. & & & -0.982 & 0.548 & 0.073 & -1.919 & 0.546 & 0 & -1.593 & 0.422 & 0.0002 \\
\hline$\geq 65$ & Ref. & & & -1.127 & 0.419 & 0.007 & -1.158 & 0.423 & 0.006 & -1.694 & 0.354 & $<0.0001$ \\
\hline \multicolumn{13}{|l|}{ Depression } \\
\hline \multicolumn{13}{|l|}{ QOL } \\
\hline \multicolumn{13}{|l|}{ Gender } \\
\hline Male & Ref. & & & -1.077 & 0.457 & 0.018 & -1.805 & 0.513 & 0 & -2.791 & 0.4 & $<0.0001$ \\
\hline Female & Ref. & & & -1.432 & 0.349 & $<0.0001$ & -2.018 & 0.343 & $<0.0001$ & -2.147 & 0.313 & $<0.0001$ \\
\hline \multicolumn{13}{|l|}{ Age } \\
\hline $45-54$ & Ref. & & & -1.991 & 0.752 & 0.008 & -2.485 & 0.747 & 0.001 & -3.786 & 0.613 & $<0.0001$ \\
\hline $55-64$ & Ref. & & & -1.303 & 0.495 & 0.008 & -2.029 & 0.501 & $<0.0001$ & -2.425 & 0.408 & $<0.0001$ \\
\hline$\geq 65$ & Ref. & & & -1.172 & 0.379 & 0.002 & -1.705 & 0.387 & $<0.0001$ & -2.292 & 0.331 & $<0.0001$ \\
\hline \multicolumn{13}{|l|}{ Depression } \\
\hline Yes & Ref. & & & -1.338 & 0.422 & 0.002 & -1.702 & 0.417 & $<0.0001$ & -2.218 & 0.349 & $<0.0001$ \\
\hline
\end{tabular}

$\beta$, regression coefficient; $\mathrm{HRQOL}$, health-related quality of life; $\mathrm{QOL}$, quality of life. 
Table 4 Subgroup analysis of change in each component of the healthy lifestyle score

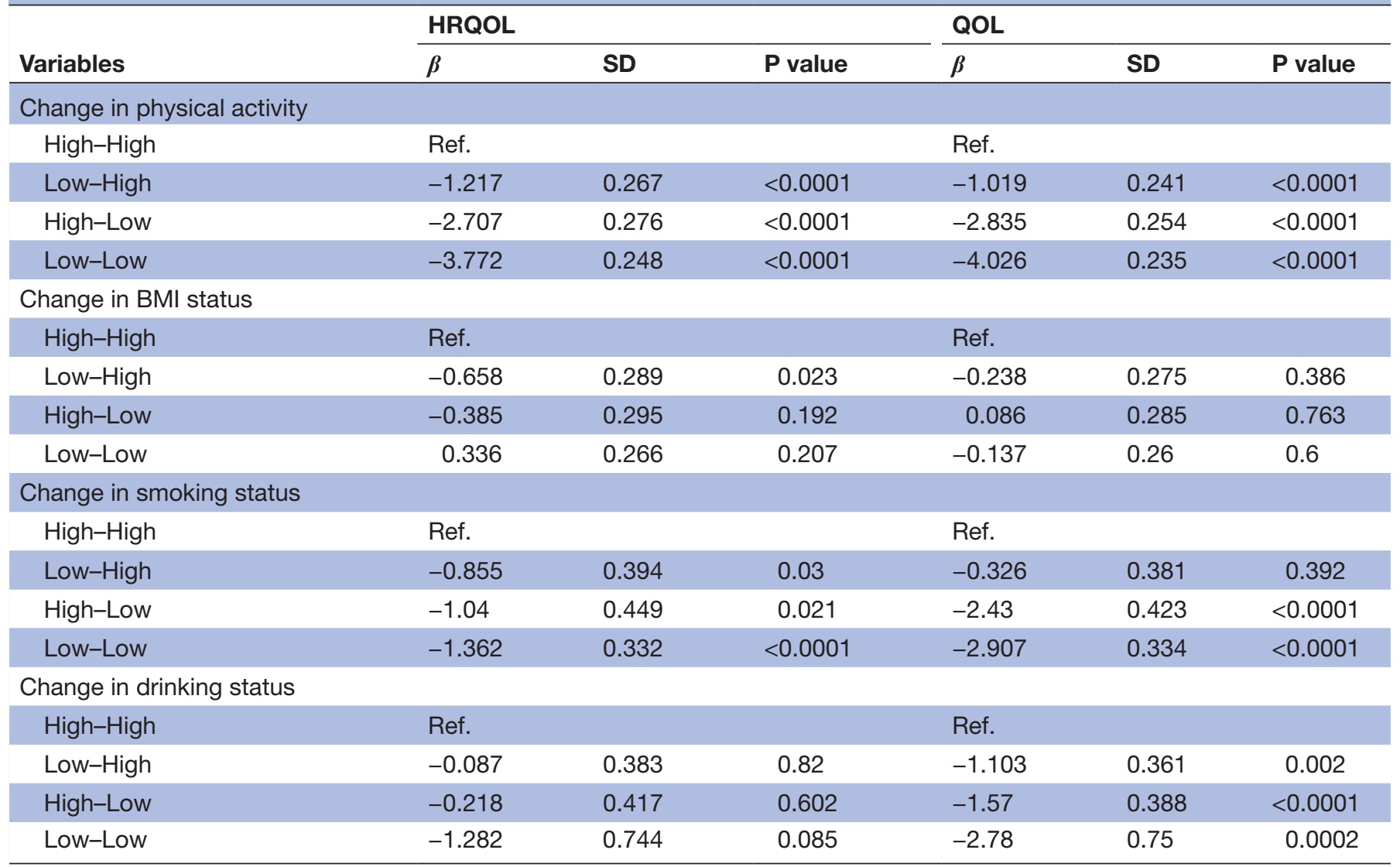

$\beta$, regression coefficient; BMI, body mass index; HRQOL, health-related quality of life; QOL, quality of life.

heavy drinking showed the lowest estimates of HRQOL and QOL, but its relationship with QOL was stronger and showed statistically significant values. A study conducted in the Norwegian general population reported that excessive drinking had the poorest QOL in various domains, namely psychological, social relationships and environmental, rather than the physical health domain. ${ }^{35}$

This study has several strengths and limitations. Due to the large and homogeneous nature of the sample, the results can be generalised to South Korean adults aged 45 years and older. Our findings both demonstrate the link between healthy lifestyle scores and the subjective evaluation of the QOL and also provide evidence supporting that among older adults, poor health behaviours may result in worse QOL, both health-related and general. However, this study has several limitations. First, the respondents' responses were subjective; therefore, recall bias may exist. Second, our findings cannot be generalised to nonKorean populations. Third, because of the use of different cut-off points of health behaviour measures, comparisons across studies are complex. ${ }^{1136}$ Fourth, as we used panel data, missing arising from loss of participants due to attrition is inevitable. Finally, we used self-reported measures of health behaviours. The use of objective measures of health behaviours, such as verifying smoking using urine cotinine, actigraphs for physical activity ${ }^{37}$ and accurate measurements of the amount and frequency of alcohol consumption might have yielded more precise estimates of a healthy lifestyle.

\section{CONCLUSION}

The present study findings suggest an association between healthy lifestyle score changes and QOL, in both overall and health-related aspects. Hence, these findings may prove to be useful in implementing future policies to support partaking in healthy lifestyle choices to improve the QOL and overall life satisfaction of the rapidly ageing population.

Contributors FN designed this study, performed the statistical analysis, and wrote the manuscript. WJ, BNJ and HJL contributed to the design of the study and provided statistical expertise and interpretation. E-CP conceived, designed and supervised the study as the guarantor. All authors read and approved the final manuscript.

Funding The authors have not declared a specific grant for this research from any funding agency in the public, commercial or not-for-profit sectors.

Competing interests None declared.

Patient consent for publication Not applicable.

Ethics approval The KLoSA study was approved by the National Statistical Office (Approval number: 33602) and was conducted after acquiring verbal consent from the study participants. As the KLOSA database has been released to the public for research purposes, ethical approval was not required for the study. There are no details of individual participants in the manuscript.

Provenance and peer review Not commissioned; externally peer reviewed. 
Data availability statement Data are available in a public, open access repository. Data are available upon reasonable request. The data used in this study is available at https://survey.keis.or.kr/eng/klosa/databoard/List.jsp.

Supplemental material This content has been supplied by the author(s). It has not been vetted by BMJ Publishing Group Limited (BMJ) and may not have been peer-reviewed. Any opinions or recommendations discussed are solely those of the author(s) and are not endorsed by BMJ. BMJ disclaims all liability and responsibility arising from any reliance placed on the content. Where the content includes any translated material, BMJ does not warrant the accuracy and reliability of the translations (including but not limited to local regulations, clinical guidelines, terminology, drug names and drug dosages), and is not responsible for any error and/or omissions arising from translation and adaptation or otherwise.

Open access This is an open access article distributed in accordance with the Creative Commons Attribution Non Commercial (CC BY-NC 4.0) license, which permits others to distribute, remix, adapt, build upon this work non-commercially, and license their derivative works on different terms, provided the original work is properly cited, appropriate credit is given, any changes made indicated, and the use is non-commercial. See: http://creativecommons.org/licenses/by-nc/4.0/.

\section{ORCID iDs}

Fatima Nari http://orcid.org/0000-0002-3031-3388

Eun-Cheol Park http://orcid.org/0000-0002-2306-5398

\section{REFERENCES}

1 World Health Organization. Ageing and health. Available: https:// www.who.int/news-room/fact-sheets/detail/ageing-and-health [Accessed 21 Jun 2020].

2 Min D, Cho E. Patterns in quality of life according to employment among the older adults: the Korean longitudinal study of aging (2008-2014). BMC Public Health 2018;18:379.

3 World Health Organization. What quality of life? the WHOQOL group. world health organization quality of life assessment. World Health Forum 1996;17:354-6.

4 DuMontier C, Clough-Gorr KM, Silliman RA, et al. Health-related quality of life in a predictive model for mortality in older breast cancer survivors. J Am Geriatr Soc 2018:66:1115-22.

5 van Groenestijn AC, Kruitwagen-van Reenen ET, Visser-Meily JMA, et al. Associations between psychological factors and healthrelated quality of life and global quality of life in patients with ALS: a systematic review. Health Qual Life Outcomes 2016;14:107.

6 Kim MA, Choi SE, Moon JH. Effect of heath behavior, physical health and mental health on heath-related quality of life in middle aged women: by using the 2014 Korea health panel data. J Korean Acad Nurs 2019;26:72-80.

7 Park M-J, Choi SE. The effects of health behavior and health status on heath-related quality of life in older people: gender analysis by using the 2012 Korea health panel data. $J$ Korean Acad Nurs 2017;28:118-28.

8 Pronk NP, Anderson LH, Crain AL, et al. Meeting recommendations for multiple healthy lifestyle factors. prevalence, clustering, and predictors among adolescent, adult, and senior health plan members. Am J Prev Med 2004;27:25-33.

9 Fong JH, Mitchell OS, Koh BSK, . Disaggregating activities of daily living limitations for predicting nursing home admission. Health Serv Res 2015;50:560-78.

10 Lee I, Kim S, Kang H. Lifestyle risk factors and all-cause and cardiovascular disease mortality: data from the Korean longitudinal study of aging. Int J Environ Res Public Health 2019;16:3040.

11 Berrigan D, Dodd K, Troiano RP, et al. Patterns of health behavior in U.S. adults. Prev Med 2003;36:615-23.

$12 \mathrm{Kim} \mathrm{KH}$, Park J, Lee SH. Data from: KLoSA 1-6th wave. Korea employment information service, 2019. Available: https://survey.keis. or.kr/eng/klosa/databoard/List.jsp

13 Choi Y, Lee K-S, Shin J, et al. Effects of a change in social activity on quality of life among middle-aged and elderly Koreans: analysis of the Korean longitudinal study of aging (2006-2012). Geriatr Gerontol Int 2017; 17:132-41.

14 Ewing JA. Detecting alcoholism. the cage questionnaire. JAMA 1984;252:1905-7.
15 World Health Organization. The Asia-Pacific perspective: redefining obesity and its treatment. Sydney: Health Communications Australia, 2000.

16 Oh E, Kang Y, Shin J. A validity study of K-MMSE as a screening test for dementia: comparison against a comprehensive neuropsychological evaluation. Dement Neurocognitive Disord 2010;9:8-12.

17 Schober P, Vetter TR. Repeated measures designs and analysis of longitudinal data: if at first you do not succeed-try, try again. Anesth Analg 2018;127:569.

18 Verger P, Lions C, Ventelou B. Is depression associated with health risk-related behaviour clusters in adults? Eur J Public Health 2009;19:618-24.

19 Harrington J, Perry IJ, Lutomski J, et al. Living longer and feeling better: healthy lifestyle, self-rated health, obesity and depression in Ireland. Eur J Public Health 2010;20:91-5.

20 Chan RHM, Gordon NF, Chong A, et al. Influence of socioeconomic status on lifestyle behavior modifications among survivors of acute myocardial infarction. Am J Cardiol 2008;102:1583-8.

21 Xavier FMF, Ferraz MPT, Marc N, et al. Elderly people's definition of quality of life. Braz J Psychiatry 2003;25:31-9.

22 Piper ME, Kenford S, Fiore MC, et al. Smoking cessation and quality of life: changes in life satisfaction over 3 years following a quit attempt. Ann Behav Med 2012;43:262-70.

23 Conry MC, Morgan K, Curry P, et al. The clustering of health behaviours in Ireland and their relationship with mental health, selfrated health and quality of life. BMC Public Health 2011;11:692.

24 Gallicchio L, Hoffman SC, Helzlsouer KJ. The relationship between gender, social support, and health-related quality of life in a community-based study in Washington County, Maryland. Qual Life Res 2007;16:777-86.

25 Noro A, Aro S. Health-Related quality of life among the least dependent institutional elderly compared with the non-institutional elderly population. Qual Life Res 1996;5:355-66.

26 Lima MG, Barros MBdeA, César CLG, et al. Impact of chronic disease on quality of life among the elderly in the state of São Paulo, Brazil: a population-based study. Rev Panam Salud Publica 2009;25:314-21.

27 Jia H, Zack MM, Gottesman II, et al. Associations of smoking, physical inactivity, heavy drinking, and obesity with quality-adjusted life expectancy among US adults with depression. Value Health 2018;21:364-71.

28 Lee S-H, Choi I, Ahn W-Y, et al. Estimating quality of life with biomarkers among older Korean adults: a machine-learning approach. Arch Gerontol Geriatr 2020;87:103966.

29 Sampaio PYS, Ito E. Activities with higher influence on quality of life in older adults in Japan. Occup Ther Int 2013;20:1-10.

30 Ryu M, Lee S, Kim H, et al. Effect of aerobic physical activity on health-related quality of life in middle aged women with osteoarthritis: Korea National health and nutrition examination survey (2016-2017). Int J Environ Res Public Health 2020;17:527.

31 Zhu Y, Wang Q, Pang G, et al. Association between body mass index and health-related quality of life: the "obesity paradox" in 21,218 adults of the Chinese general population. PLoS One 2015;10:e0130613.

32 Maxwell CJ, Hirdes JP. The prevalence of smoking and implications for quality of life among the community-based elderly. Am J Prev Med 1993;9:338-45.

33 Mesquita R, Gonçalves CG, Hayashi D, et al. Smoking status and its relationship with exercise capacity, physical activity in daily life and quality of life in physically independent, elderly individuals. Physiotherapy 2015;101:55-61.

34 Lee TW, Ko IS, Lee KJ. Health promotion behaviors and quality of life among community-dwelling elderly in Korea: a cross-sectional survey. Int J Nurs Stud 2006;43:293-300.

35 Mathiesen EF, Nome S, Eisemann M, et al. Drinking patterns, psychological distress and quality of life in a Norwegian general population-based sample. Qual Life Res 2012;21:1527-36.

36 Schneider S, Huy C, Schuessler M, et al. Optimising lifestyle interventions: identification of health behaviour patterns by cluster analysis in a German 50+ survey. Eur J Public Health 2009;19:271-7.

37 Stringhini S, Sabia S, Shipley M, et al. Association of socioeconomic position with health behaviors and mortality. JAMA 2010;303:1159-66. 